\title{
Disturbance Observer-Based Backstepping Control of PMSM for the Mine Traction Electric Locomotive
}

\author{
Jiande Yan $\mathbb{D}$, ${ }^{1,2}$ Hui Wang, ${ }^{1}$ Shoudao Huang, ${ }^{1}$ and Yonghong Lan $\mathbb{D}^{3}$ \\ ${ }^{1}$ College of Electrical and Information Engineering, Hunan University, Changsha, Hunan 410082, China \\ ${ }^{2}$ College of Electrical and Information, Hunan Institute of Engineering, Xiangtan, Hunan 411100, China \\ ${ }^{3}$ College of Information Engineering, Xiangtan University, Xiangtan 411105, China \\ Correspondence should be addressed to Jiande Yan; 40334732@qq.com
}

Received 11 December 2017; Revised 28 March 2018; Accepted 17 April 2018; Published 15 May 2018

Academic Editor: Xue-Jun Xie

Copyright (C) 2018 Jiande Yan et al. This is an open access article distributed under the Creative Commons Attribution License, which permits unrestricted use, distribution, and reproduction in any medium, provided the original work is properly cited.

\begin{abstract}
For the Permanent Magnet Synchronous Motor (PMSM) control system of the Mine Traction Electric Locomotive (MTEL), the fluctuation of the load will lead to the resonance of the velocity of the MTEL. In addition, the speed sensor is easy to be damaged due to the moisture, dust, and vibration. To solve the above problems, a disturbance observer-based (DOB) backstepping control of PMSM for the MTEL is proposed in this paper. First, a full-dimensional Luenberger observer for PMSM is designed and the asymptotically stability of the observer is proved. Next, through the designing of the virtual control input that includes the reconstruction disturbances and using backstepping control strategy, the DOB controller is proposed. The obtained controller can achieve high precision speed tracking and disturbance rejection. Finally, the effectiveness and feasibility of the designed system are verified by Matlab simulation and experiment results.
\end{abstract}

\section{Introduction}

With the development of power electronics technology and control technology, PMSM has been widely applied in various industrial sectors due to its compact size, high torque/inertia ratio, high torque/weight ratio, and absence of rotor loss [1]. However, PMSM is a complicated high-order, nonlinear system with multiple variables and strong coupling characteristics as well as external disturbances. Over the last decades, various design methods have been developed [2-4].

To gain the information on rotor speed and position of the motor, a commonly used control strategy is to install an encoder or other kinds of sensors on the rotor shaft, but it would increase the system cost and reduce the system reliability. In recent years, to enhance the system performance and reduce the adverse effects of sensors on the system, much attention has been given to achieve sensorless operation [3-6]. In [7], a model reference adaptive system (MRAS) technique has been used for speed estimation in sensorless speed control of PMSM. To obtain the rotor speed of the motor, a reduced-order linear Luenberger observer was proposed in [8]. However, the rate of convergence for the Luenberger observer was determined through pole assignment. Furthermore, a passive full-order observer was designed to estimate rotor speed. In order to improve the robustness and accuracy of position and speed estimations, the sliding-mode observers were widely used in very recent years. However, the chattering phenomenon in sliding-mode observer is the major drawback [9].

The disturbance observer does not need to establish accurate mathematical model for the disturbance signal [10]. Recently, disturbance observer-based (DOB) control methods have been applied to PMSM system for better robustness against system disturbance [11]. On the basis of disturbance observer, sliding model controller was adopted to realize Permanent Magnet Synchronous Motor control proposed in [12], but the control design of low pass filter is sensitive to the noise. In [13], an integral state observer-based controller was designed to improve disturbance rejection performance of PMSM. In [14], a DOB state feedback controller was designed for PMSM system. By using the same disturbance observer, a sensorless control method for PMSM drive was developed 
in [15]. The proposed DOB controller involved the use of a back electromotive force observer and a torque observer to estimate rotor position and compensate for load torque disturbance, respectively. For the mismatched disturbance, in [16], a DOB integral sliding-mode control approach for linear systems with mismatched disturbances was presented. The disturbance observer is proposed to generate the disturbance estimate, which can be incorporated in the controller to counteract the disturbance. In [17], the load factor of friction was considered and the sliding-mode variable structure controller was designed. Using nonlinear disturbance observer to approximate system uncertainty, a disturbance observerbackstepping control was proposed in [18]. However, the observer and controller are designed separately.

Motivated by the discussions above, in this paper, we mainly investigate backstepping speed control for PMSM based on disturbance observer. The contributions include the following: (1) A nonlinear disturbance observer is first constructed to estimate the external slowly time varying disturbance by using system state variables. (2) Based on Lyapunov stability theory, the linear matrix inequality- (LMI) based design method of DOB is obtained. (3) Based on backstepping control theory, the PMSM rotor speed and current tracking controllers are designed. Meanwhile, global asymptotic stability is guaranteed by Lyapunov stability analysis.

The rest of this paper is organized as follows. In Section 2, the mathematic model of PMSM and problem formulation are presented. The LMI-based nonlinear disturbance observer design and stability analysis as well as the DOB backstepping controller design method are obtained in Section 3. The system simulation and experimental results are presented in Section 4. Some conclusions are drawn in Section 5 .

\section{Mathematical Model of Permanent Magnet Synchronous Motor}

Assuming that the magnetic circuit of PMSM is unsaturated, magnetic hysteresis and eddy current loss are ignored; the traditional mathematical model of the PMSM can be given by the following equations under the $d-q$ coordinate framework $[3,13-16]$ :

$$
\begin{aligned}
& \frac{d i_{d}}{d t}=-\frac{R}{L} i_{d}+P w i_{q}+\frac{1}{L} u_{d}+\frac{1}{L} d_{1}, \\
& \frac{d i_{q}}{d t}=-\frac{R}{L} i_{q}-P w i_{d}-\frac{P \varphi}{L} w+\frac{1}{L} u_{q}+\frac{1}{L} d_{2}, \\
& \frac{d w}{d t}=\frac{3 P \varphi}{2 J} i_{q}-\frac{B}{J} w-\frac{T_{L}}{J},
\end{aligned}
$$

where $u_{d}, u_{q}$ are $d-q$ axis stator voltages; $i_{d}, i_{q}$ are $d-q$ axis stator currents; $R$ is the stator resistor; $L$ is the stator inductance; and $T_{L}$ is load torque. $J$ is the rotation inertia, $B$ is the viscosity friction coefficient, $P$ is the pole pair, $w$ is the rotor mechanical angular velocity, and $d_{1}, d_{2}$ are external disturbance. Without loss of generality, we assume that the disturbances are slowly time varying; that is, $\dot{d}_{1}=0, \dot{d}_{2}=0$.
Define $x=\left[\begin{array}{lll}w & i_{q} & i_{d}\end{array}\right]^{T}$; according to (1), the mathematical model of PMSM can be written as follows:

$$
\begin{aligned}
& \dot{x}=A x+\phi(x)+\eta+B u+B d, \\
& y=C x,
\end{aligned}
$$

where

$$
\begin{aligned}
& A=\left[\begin{array}{ccc}
-\frac{B}{J} & \frac{3 P \varphi}{2 J} & 0 \\
-\frac{P \varphi}{L} & -\frac{R}{L} & 0 \\
0 & 0 & -\frac{R}{L}
\end{array}\right], \\
& B=\left[\begin{array}{cc}
0 & 0 \\
\frac{1}{L} & 0 \\
0 & \frac{1}{L}
\end{array}\right] \text {, } \\
& C=\left[\begin{array}{lll}
0 & 1 & 0
\end{array}\right] \text {, } \\
& \phi(x)=\left[\begin{array}{c}
0 \\
-P w i_{d} \\
P w i_{q}
\end{array}\right], \\
& \eta=\left[\begin{array}{c}
-\frac{T_{L}}{J} \\
0 \\
0
\end{array}\right] \text {, } \\
& d=\left[\begin{array}{l}
d_{1} \\
d_{2}
\end{array}\right] .
\end{aligned}
$$

In this paper, the main control objective is to design a DOB backstepping controller to keep all the signals in the closed loop system bounded and ensure global asymptotic convergence of the desired speed and current tracking errors to zero eventually.

\section{Controller Design}

3.1. Design of LMI-Based Disturbance Observer. In this section, for nonlinear system (2), assume that the nonlinear function $\phi(x)$ is Lipschitz; that is, for all $x_{1}, x_{2} \in R$,

$$
\left\|\phi\left(x_{1}, u\right)-\phi\left(x_{2}, u\right)\right\|<r\left\|x_{1}-x_{2}\right\|,
$$

where $r$ is Lipschitz constant.

Based on the above assumption, the observer of nonlinear system (2) is designed as

$$
\begin{aligned}
& \dot{\hat{x}}=A \hat{x}+\phi(\hat{x}, u)+B u+\eta+L_{1}(y-\hat{y})+B \hat{d}, \\
& \hat{y}=C \hat{x}, \\
& \dot{\vec{d}}=L_{2}(y-\hat{y}),
\end{aligned}
$$

where $L_{1}=\left[\begin{array}{lll}L_{11} & L_{12} & L_{13}\end{array}\right]$ and $L_{2}$ is observer gain matrix to be determined. 

form:

The nonlinear observer (5) can be written in the following

$$
\begin{aligned}
\frac{d \hat{i}_{d}}{d t}= & -\frac{R}{L} \widehat{i}_{d}+P \widehat{w} \widehat{i}_{q}+L_{13}\left(i_{q}-\hat{i}_{q}\right)+\frac{1}{L} u_{d}+\frac{1}{L} \widehat{d}_{1}, \\
\frac{d \hat{i}_{q}}{d t}= & -\frac{R}{L} \widehat{i}_{q}-P \widehat{w} \widehat{i}_{d}-\frac{P \varphi}{L} \widehat{w}+L_{12}\left(i_{q}-\widehat{i}_{q}\right)+\frac{1}{L} u_{q} \\
& +\frac{1}{L} \widehat{d}_{2}, \\
\frac{d \widehat{w}}{d t}= & \frac{3 P \varphi_{\hat{i}}}{2 J} \hat{i}_{q}-\frac{B}{J} \widehat{w}+L_{1}\left(i_{q}-\widehat{i}_{q}\right)-\frac{T_{L}}{J} .
\end{aligned}
$$

Defining the observer error $e_{x}=x(t)-\widehat{x}(t), e_{d}=d-\widehat{d}$, we have

$$
\begin{aligned}
& e_{x}=A_{C} \widehat{x}(t)+\phi(x)-\phi(\widehat{x})+B e_{d}, \\
& e_{d}=-L_{2} C e_{x} .
\end{aligned}
$$

Setting $e=\left[e_{x}, e_{d}\right]$, we have

$$
\dot{e}=(\bar{A}-\bar{L} \bar{C}) e(t)+\widetilde{\phi},
$$

where $\bar{A}=\left[\begin{array}{cc}A & B \\ 0 & 0\end{array}\right], \bar{L}=\left[\begin{array}{l}L_{1} \\ L_{2}\end{array}\right], \bar{C}=[C, 0], \tilde{\phi}=\left[\begin{array}{c}\phi(x)-\phi(\widehat{x}) \\ 0\end{array}\right]$.

Thus, the design problem of observer is transformed into the stability problem of error system (9). To obtain an LMIbased observer design method, the following Lemmas are necessary.

Lemma 1 (see [19]). Given real matrices $H$ and $E$ of appropriate dimensions,

$$
H F(t) E+E^{T} F^{T}(t) H^{T}<0
$$

for all $F(t)$ satisfying $F^{T}(t) F(t) \leq I$, if and only if there exists a constant $\xi>0$, such that

$$
\xi H H^{T}+\xi^{-1} E^{T} E<0 .
$$

Lemma 2 (Schur complement [20]). For a real matrix $\Omega=$ $\Omega^{T}$, the following conclusions are equivalent:

(1) $\Omega:=\left[\begin{array}{cc}\Omega_{11} & \Omega_{12} \\ * & \Omega_{22}\end{array}\right]>0$;

(2) $\Omega_{11}>0$, and $\Omega_{22}-\Omega_{12}^{T} \Omega_{11}{ }^{-1} \Omega_{12}>0$;

(3) $\Omega_{22}>0$, and $\Omega_{11}-\Omega_{12}^{T} \Omega_{22} \Omega_{12}>0$.

Based on the above Lemmas and applying Lyapunov stability theory, the design method of LMI-based observer can be obtained by the following result.

Theorem 3. For nonlinear systems (2), suppose that the observer holds the form (5); if there exist symmetrical positive definite matrix $P$ and matrix $W$ of appropriate dimensions together with real scalar $\varepsilon>0$, such that

$$
\left[\begin{array}{cc}
\Pi & P \\
* & -\varepsilon I
\end{array}\right]<0,
$$

where $\Pi=P \bar{A}+\bar{A}^{T} P-W \bar{C}-\bar{C}^{T} W^{T}+\varepsilon r^{2} I$, then the error dynamics (10) is asymptotically stable. Furthermore, the observer gain can be chosen as $\bar{L}=P^{-1} W$.

Proof. Define monochromatic Lyapunov function as $V=$ $e(t)^{T} P e(t)$; taking the derivative along system (10), we have

$$
\begin{aligned}
V & =e(t)^{T} P e(t)+e(t)^{T} P e(t) \\
& =e(t)^{T}\left(\bar{A}_{C}{ }^{T} P+P \bar{A}_{C}\right) e(t)+2 e(t)^{T} P \phi,
\end{aligned}
$$

where $A_{C}=\bar{A}-\bar{L} \bar{C}$.

Using Lemma 1 and condition (4), we can obtain

$$
\begin{aligned}
& 2 e(t)^{T} P(\phi(x, u)-\phi(\hat{x}, u)) \\
& \quad \leqslant \varepsilon^{-1} e(t)^{T} P^{2} e(t)+\varepsilon r^{2} e(t)^{T} e(t) .
\end{aligned}
$$

Combined with the above formula, inequality (14) is equivalent to

$$
\dot{V} \leqslant e(t)^{T}\left(A_{C}{ }^{T} P+P A_{C}+\varepsilon^{-1} P^{2}+\varepsilon r^{2} I\right) e(t) .
$$

If we define

$$
\begin{aligned}
\Psi & =\bar{A}^{T} P+P \bar{A}-P \bar{L} \bar{C}-(P \bar{L} \bar{C})^{T}+\varepsilon^{-1} P^{2}+\varepsilon r^{2} I \\
& <0,
\end{aligned}
$$

then

$$
\dot{V} \leqslant \lambda_{\min }(\Psi)\|e(t)\|^{2}=-\partial\|e(t)\|^{2}, \quad \partial>0 .
$$

By the stability theory of Lyapunov, the observer dynamic error system (10) is asymptotically stable. Besides, seeing $W=$ $P \bar{L}$ and applying the Schur complement, inequality $\Psi<0$ is equivalent to (13). The proof is completed.

3.2. DOB Backstepping Controller Design. Backstepping control is an efficient method for nonlinear system. In this paper, the disturbance observer-based backstepping (DBS) control design can be established by the following three steps.

Step 1. Consider the motor rotor mechanical angular velocity dynamics

$$
\frac{d w}{d t}=\frac{3 P \varphi}{2 J} i_{q}-\frac{B}{J} w-\frac{T_{L}}{J} .
$$

In the first step of the design of backstepping control, a virtual control input of the motor speed $w$ has to be determined. Let $w^{*}$ be the desired trajectory and $w^{*}=0$. Define the speed tracking error $e_{w}=w^{*}-w$; thus

$$
\begin{aligned}
\dot{e}_{w} & =\frac{B}{J} w-\frac{3 P \varphi}{2 J} i_{q}+\frac{T_{L}}{J} \\
& =\frac{1}{J}\left(B \widetilde{w}+B \widehat{w}+T_{L}-\frac{3 P \varphi_{\hat{i}_{q}}}{2}-\frac{3 P \varphi_{\widehat{i}}}{2} \hat{i}_{q}\right),
\end{aligned}
$$

where $\widetilde{w}=w-\widehat{w}$ and $\widetilde{i}_{q}=i_{q}-\widehat{i}_{q}$. 
Define the first Lyapunov function as

$$
V_{1}=\frac{1}{2} K \theta^{2}+\frac{1}{2} e_{w}^{2}+V
$$

where $V=e(t)^{T} P e(t), \theta$ is the integral of the velocity error, $K>0, \theta=\int_{0}^{t} e_{w} d \tau$. have

Taking the derivative of $V_{1}$ and using inequality (18), we

$$
\begin{aligned}
\dot{V}_{1}= & K \theta \dot{\theta}+e_{w} \dot{e}_{w}+\dot{V} \leq K \theta \dot{\theta}+e_{w} \dot{e}_{w}-\partial\|e(t)\|^{2} \\
= & \frac{e_{w}}{J}\left(K J \theta+B \widetilde{w}+B \widehat{w}+T_{L}-\frac{3 P \varphi_{\widetilde{i}}}{2} \dot{i}_{q}-\frac{3 P \varphi_{\widehat{i}}}{2} \dot{i}_{q}\right) \\
& -\partial\|e(t)\|^{2} .
\end{aligned}
$$

Define the virtual control input

$$
\widehat{i}_{q}=\frac{2 J}{3 P \varphi}\left(\frac{B}{J} \widehat{w}+c_{1} e_{w}+\frac{T_{L}}{J}+K \theta\right),
$$

where $c_{1}>0$.

Therefore,

$$
\dot{V}_{1} \leqslant-c_{1} e_{w}^{2}+\frac{e_{w}}{J}\left(B \widetilde{w}-\frac{3 P \varphi_{\widetilde{i}}}{2} \dot{i}_{q}\right)-\partial\|e(t)\|^{2} .
$$

Using the classical inequality $\pm a b \leqslant \varepsilon a^{2}+(1 / 4 \varepsilon) b^{2}(\varepsilon>0)$ yields

$$
\begin{aligned}
\dot{V}_{1} \leqslant & -c_{1} e_{w}^{2}+\frac{B}{J}\left(\varepsilon_{1} e_{w}^{2}+\frac{1}{4 \varepsilon_{1}} \widetilde{w}^{2}\right) \\
& +\frac{3 P \varphi}{2}\left(\varepsilon_{2} e_{w}^{2}+\frac{1}{4 \varepsilon_{2}} \widetilde{i}_{q}^{2}\right)-\partial\|e(t)\|^{2} \\
\leqslant & -\left(c_{1}-\frac{B}{J} \varepsilon_{1}-\frac{3 P \varphi}{2} \varepsilon_{2}\right) e_{w}^{2} \\
& -\left(\partial-\frac{B}{4 J \varepsilon_{1}}-\frac{3 P \varphi}{8 J \varepsilon_{2}}\right)\|e(t)\|^{2} \\
= & -C_{1} e_{w}^{2}-C_{2}\|e(t)\|^{2},
\end{aligned}
$$

where $C_{1}=c_{1}-(B / J) \varepsilon_{1}-(3 P \varphi / 2) \varepsilon_{2}, C_{2}=\partial-B / 4 J \varepsilon_{1}-$ $3 P \varphi / 8 J \varepsilon_{2}$. If the parameters $\varepsilon_{1}>0, \varepsilon_{2}>0$ and $c_{1}$ are properly selected such that $C_{1}>0, C_{2}>0$, then

$$
\dot{V}_{1} \leqslant-C_{1} e_{w}^{2}-C_{2}\|e(t)\|^{2}<0
$$

which ensures that the speed tracking error will converge asymptotically to zero.

Step 2. According to (23), the virtual input current of the $q$ axis can be chosen as

$$
\widehat{i}_{q}^{*}=\frac{2 J}{3 P \varphi}\left(\frac{B}{J} \widehat{w}+C_{1} e_{w}+\frac{T_{L}}{J}+K \theta\right) .
$$

Define the $q$ axis current tracking error $e_{q}=\widehat{i}_{q}^{*}-\widehat{i}_{q}$. Choose the second Lyapunov function to stabilize $q$ axis current tracking error dynamics as

$$
V_{2}=\frac{1}{2} e_{q}^{2}+V_{1}
$$

From (7), (8), and (27), the following result can be easily obtained:

$$
\begin{aligned}
\dot{e}_{q}= & \frac{2}{3 P \varphi}\left(B \dot{\widehat{w}}+C_{1} \dot{e}_{w}+K J \dot{\theta}\right)-\frac{\widehat{i}_{q}}{d t} \\
= & \frac{2 B}{3 P \varphi}\left(\frac{3 P \varphi}{2 J} \hat{i}_{q}-\frac{B}{J} \widehat{w}-\frac{T_{L}}{J}+L_{1} \hat{i}_{q}\right)+\frac{2 C_{1} J}{3 P \varphi} \dot{e}_{w} \\
& +\frac{R}{L} \widehat{i}_{q}+P \widehat{w} \hat{i}_{d}+\frac{P \varphi}{L} \widehat{w}-\frac{1}{L} u_{q}-L_{2} \vec{i}_{q}-\frac{1}{L} \widehat{d}_{1} .
\end{aligned}
$$

Substituting (20) into (29), we have

$$
\begin{aligned}
\dot{e}_{q}= & \frac{2 B}{3 P \varphi}\left(\frac{3 P \varphi_{\widehat{i}}}{2 J}-\frac{B}{J} \widehat{w}-\frac{T_{L}}{J}+L_{1} \widetilde{i}_{q}\right) \\
& -\frac{2 C_{1} J}{3 P \varphi}\left(\frac{3 P \varphi}{2}\left(\widetilde{i}_{q}+\widehat{i}_{q}\right)-B(\widetilde{w}+\widehat{w})-T_{L}\right) \\
& +\frac{R}{L} \widehat{i}_{q}+P \widehat{w} \widehat{i}_{d}+\frac{P \varphi}{L} \widehat{w}-\frac{1}{L} u_{q}-L_{2} \tilde{i}_{q}-\frac{2 C_{1} K J}{3 P \varphi} \theta \\
& -\frac{1}{L} \widehat{d}_{1} \\
= & \left(\frac{B}{J}+\frac{R}{L}\right) \hat{i}_{q}+\left(\frac{P \varphi}{L}-\frac{2 B}{3 J P \varphi}\right) \widehat{w}+P \widehat{w} \hat{i}_{d} \\
& -\frac{2 C_{1} K J}{3 P \varphi} \theta-\frac{2 T_{L} B}{3 J P \varphi}+\left(\frac{2 B L_{1}}{3 J P \varphi}-C_{1}-L_{2}\right) \tilde{i}_{q} \\
& -\frac{u_{q}}{L}-\frac{2 J B\left(C_{1}^{2}-K\right)}{3 P \varphi} e_{w} \frac{1}{L} \widehat{d}_{1} .
\end{aligned}
$$

Define

$$
\begin{aligned}
\Theta= & \left(\frac{B}{J}+\frac{R}{L}\right) \widehat{i}_{q}+\left(\frac{P \varphi}{L}-\frac{2 B^{2}}{3 J P \varphi}\right) \widehat{w}+P \widehat{w} \widehat{i}_{d}-\frac{2 T_{L} B}{3 J P \varphi} \\
& -\left(\frac{2 C_{1}^{2} J}{3 P \varphi}-\frac{2 K J}{3 P \varphi}\right) e_{w}-\frac{2 C_{1} K J}{3 P \varphi} \theta-\frac{1}{L} \widehat{d}_{1} .
\end{aligned}
$$

Then

$$
\dot{e}_{q}=\Theta+\frac{2 B C_{1}}{3 J P \varphi} \widetilde{w}+\left(\frac{2 B L_{1}}{3 J P \varphi}-C_{1}-L_{2}\right) \tilde{i}_{q}-\frac{u_{q}}{L}
$$

The derivative of $V_{2}$ time $t$ is given by

$$
\begin{aligned}
\dot{V}_{2}= & e_{q} \dot{e}_{q}+\dot{V}_{1} \\
\leqslant & -C_{1} e_{w}^{2}-C_{2}\|e(t)\|^{2}+\frac{2 B C_{1}}{3 J P \varphi} \widetilde{w} \\
& +\left(\frac{2 B L_{1}}{3 J P \varphi}-C_{1}-L_{2}\right) \widetilde{i}_{q}+\left(\Theta-\frac{u_{q}}{L}\right) e_{q} .
\end{aligned}
$$


In order to keep the $q$-axis current tracking error asymptotically stable, the control law $u_{q}$ can be selected as

$$
\begin{aligned}
u_{q} & =L \Theta+L C_{2} e_{q}=L\left[\left(\frac{B}{J}+\frac{R}{L}\right) \widehat{i}_{q}\right. \\
& +\left(\frac{P \varphi}{L}-\frac{2 B^{2}}{3 J P \varphi}\right) \widehat{w}+P \widehat{w} \widehat{i}_{d}-\left(\frac{2 C_{1}^{2} J}{3 P \varphi}-\frac{2 K J}{3 P \varphi}\right) e_{w} \\
& \left.-\frac{2 C_{1} K J}{3 P \varphi} \theta+C_{2} e_{q}\right]-\widehat{d}_{1} .
\end{aligned}
$$

Further, consider the following inequalities:

$$
\begin{aligned}
& \left(\frac{2 B L_{1}}{3 J P \varphi}-C_{1}-L_{2}\right) \widetilde{i}_{q} e_{q} \\
& \quad \leqslant\left(\frac{2 B L_{1}}{3 J P \varphi}-C_{1}-L_{2}\right)\left(\varepsilon_{3} e_{q}^{2}+\frac{1}{4 \varepsilon_{3}} \widetilde{i}_{q}\right), \\
& \frac{2 B C_{1}}{3 J P \varphi} \widetilde{w} e_{q} \leqslant \frac{2 B C_{1}}{3 J P \varphi}\left(\varepsilon_{4} e_{q}^{2}+\frac{1}{4 \varepsilon_{3}} \widetilde{w}^{2}\right),
\end{aligned}
$$

where $\varepsilon_{3}, \varepsilon_{4}$ are positive real numbers. Therefore, inequality (33) can be further simplified as

$$
\begin{aligned}
\dot{V}_{2} \leqslant & -C_{1} e_{w}^{2}-\left(C_{2}-C_{3}-\frac{B c_{1}}{6 \varepsilon_{4} J P \varphi}\right)\|e(t)\|^{2} \\
& -\left(C_{2}-C_{4}-\frac{2 B c_{1}}{3 J P \varphi} \varepsilon_{4}\right) e_{q}^{2},
\end{aligned}
$$

where $C_{3}=\left(1 / 4 \varepsilon_{3}\right)\left(2 B L_{1} / 3 J P \varphi-C_{1}-L_{2}\right), C_{4}=\varepsilon_{3}\left(2 B L_{1} /\right.$ $\left.3 J P \varphi-C_{1}-L_{2}\right)$.

If choosing the right parameter $C_{3}, C_{4}$ satisfies the following conditions:

$$
\begin{gathered}
C_{2}-C_{3}-\frac{1}{4 \varepsilon_{3}}>0, \\
C_{2}-C_{4}-C_{1} \varepsilon_{4}>0,
\end{gathered}
$$

then $\dot{V}_{2}<0$. Thus, the dynamic error of $q$-axis current is asymptotically stable.

Step 3. The expected value of $d$-axis current is $\widehat{i}_{d}^{*}=0$. Define the tracking error as follows:

$$
e_{d}=\widehat{i}_{d}^{*}-\hat{i}_{d}
$$

The derivative of $e_{d}$ is

$$
\dot{e}_{d}=\frac{d \hat{i}_{d}^{*}}{d t}-\frac{d \hat{i}_{d}}{d t}=\frac{R}{L} \widehat{i}_{d}-P \widehat{w} \widehat{i}_{q}-\frac{1}{L} u_{d}-L_{3} \widehat{i}_{q}-\frac{1}{L} \widehat{d}_{2} .
$$

Select the third Lyapunov function as

$$
V_{3}=V_{2}+\frac{1}{2} e_{d}^{2}
$$

which results in

$$
\begin{aligned}
\dot{V}_{3}= & \dot{V}_{2}+e_{d} \dot{e}_{d} \\
\leqslant & -C_{1} e_{w}^{2}-\left(C_{2}-C_{3}-\frac{B c_{1}}{6 \varepsilon_{4} J P \varphi}\right)\|e(t)\|^{2} \\
& -\left(C_{2}-C_{4}-\frac{2 B c_{1}}{3 J P \varphi} \varepsilon_{4}\right) e_{q}^{2} \\
& +e_{d}\left(\frac{R}{L} \widehat{i}_{d}-P \widehat{w} \widehat{i}_{q}-\frac{1}{L} u_{d}-L_{3} \widetilde{w}\right)-\frac{1}{L} \widehat{d}_{2} .
\end{aligned}
$$

If we select the control law $u_{d}$ as

$$
u_{d}=R \widehat{i}_{d}-P L \widehat{w}_{q}+L c_{3} e_{d},\left(C_{2}>0\right)-\widehat{d}_{2},
$$

then inequality (41) can be reduced to

$$
\begin{aligned}
\dot{V}_{3} \leqslant & -C_{1} e_{w}^{2}-\left(C_{2}-C_{3}-\frac{B c_{1}}{6 \varepsilon_{4} J P \varphi}\right)\|e(t)\|^{2} \\
& -\left(C_{2}-C_{4}-\frac{2 B c_{1}}{3 J P \varphi} \varepsilon_{4}\right) e_{q}^{2}-c_{3} e_{d}^{2}-L_{3} e_{d} \widetilde{w} .
\end{aligned}
$$

Based on inequality $-L_{3} e_{d} \widetilde{w} \leqslant \varepsilon_{5} L_{3} e_{d}^{2}+L_{3} \widetilde{w}^{2} / 4 \varepsilon_{5}, \varepsilon_{5}>$ 0 ,inequality (43) can be rewritten as

$$
\begin{aligned}
\dot{V}_{3} \leqslant & -\left(C_{2}-C_{3}-\frac{B c_{1}}{6 \varepsilon_{4} J P \varphi}-\frac{L_{3}}{4 \varepsilon_{3}}\right)\|e(t)\|^{2} \\
& -\left(C_{2}-C_{4}-\frac{2 B c_{1}}{3 J P \varphi} \varepsilon_{4}\right) e_{q}^{2}-\left(C_{3}-\varepsilon_{5} L_{3}\right) e_{d}^{2} \\
& -C_{1} e_{w}^{2} .
\end{aligned}
$$

If the parameters $C_{1}, C_{2}, C_{3}$ and $\varepsilon_{4}, \varepsilon_{5}$ are properly selected such that

$$
\begin{aligned}
C_{2}-C_{3}-\frac{B C_{1}}{6 \varepsilon_{4} J P \varphi}-\frac{L_{3}}{4 \varepsilon_{3}}>0, \\
C_{2}-C_{4}-\frac{2 B C_{1}}{3 J P \varphi} \varepsilon_{4}>0, \\
C_{3}-\varepsilon_{5} L_{3}>0,
\end{aligned}
$$

then $\dot{V}_{3}<0$, which indicates that the $d$-axis current dynamic error is also asymptotically stable. The objective of tracking control of PMSM is completed.

\section{Numerical Simulation and Experimental Results}

In this section, the numerical example and experimental results are presented to demonstrate the validity of the proposed DBS control scheme. The MATLAB/Simulink model of the proposed DBS control system is shown in Figure 1.

The experimental platform is a MTEL as shown in Figure 2. The structure of the MTEL is shown in Figure 3. MTEL have two wheel sets, and each wheel set is equipped 


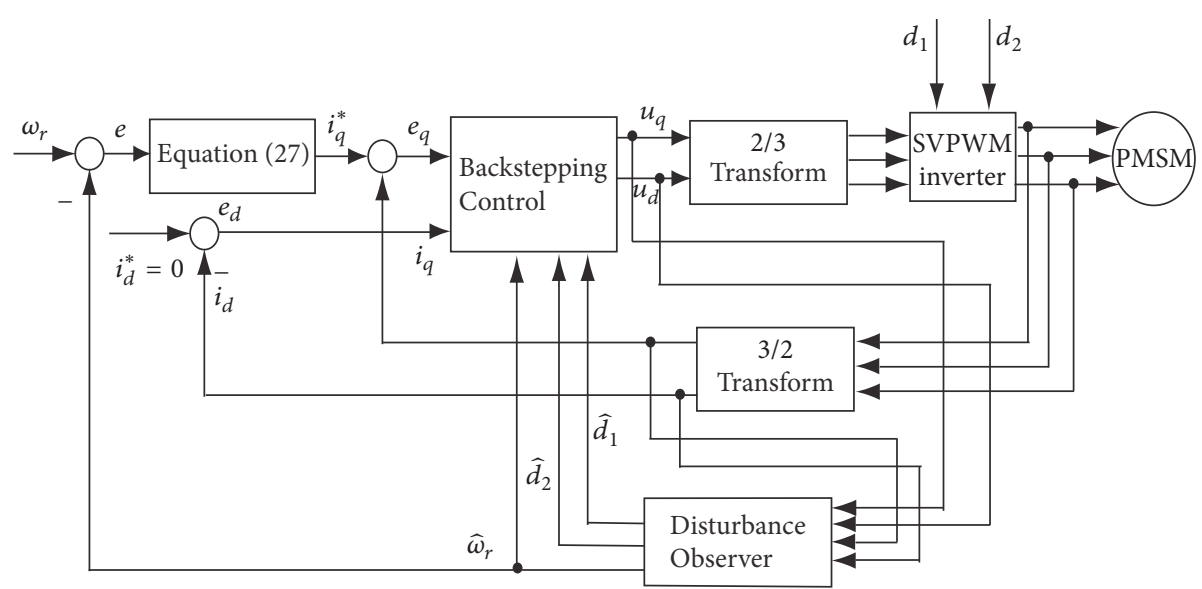

FIGURE 1: Block diagram of the sensorless PMSM control system.

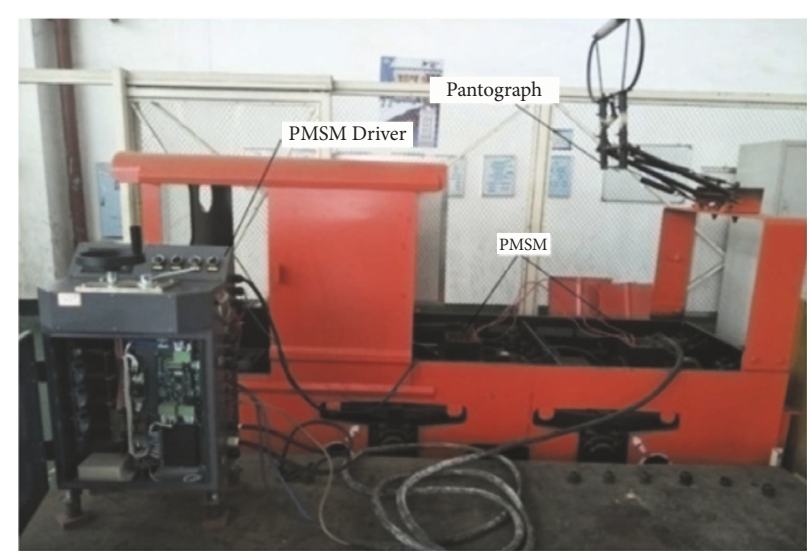

FIGURE 2: Experimental platform.

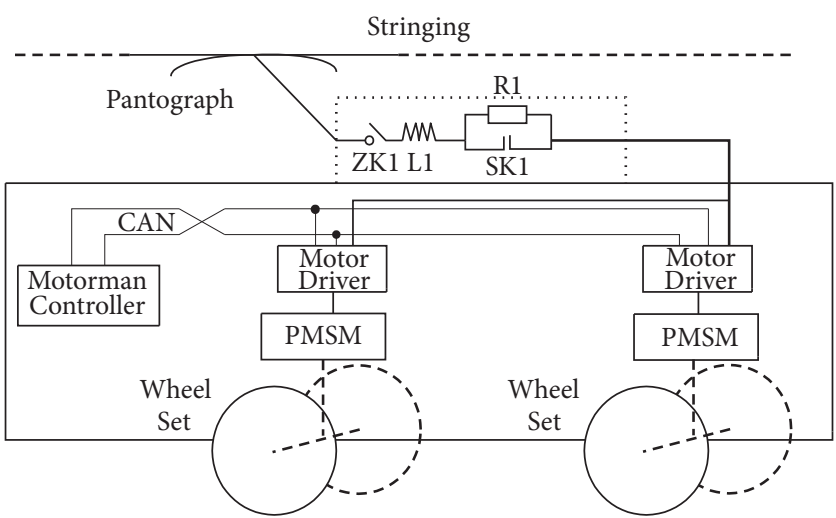

FIgURE 3: The structure of the MTEL.

with a PMSM, while the PMSM is driven by motor driver. Stringing provides $550 \mathrm{~V}$ direct current, which is power for the MTEL, MTEL takes electricity power from the stringing through pantograph.

The experimental platform is a Mine Traction Electric Locomotive (MTEL) as shown in Figure 2. The structure of the MTEL is shown in Figure 3. MTEL has two wheel sets, and each wheel set is equipped with a PMSM, while the PMSM is driven by motor driver. Stringing provides $550 \mathrm{~V}$ direct current, which is power for the MTEL; MTEL takes electricity power from the stringing through pantograph.

The electrical schematic diagram of the MTEL driving system is shown in Figure 4. It is mainly composed of two PMSM (22 kW, $380 \mathrm{~V}, 3$ pole pairs), PMSM driver, pantograph, circuit breaker (ZK1), flat wave reactor (L1), charging resistance (R1) and contactor (SK1), and the motorman 


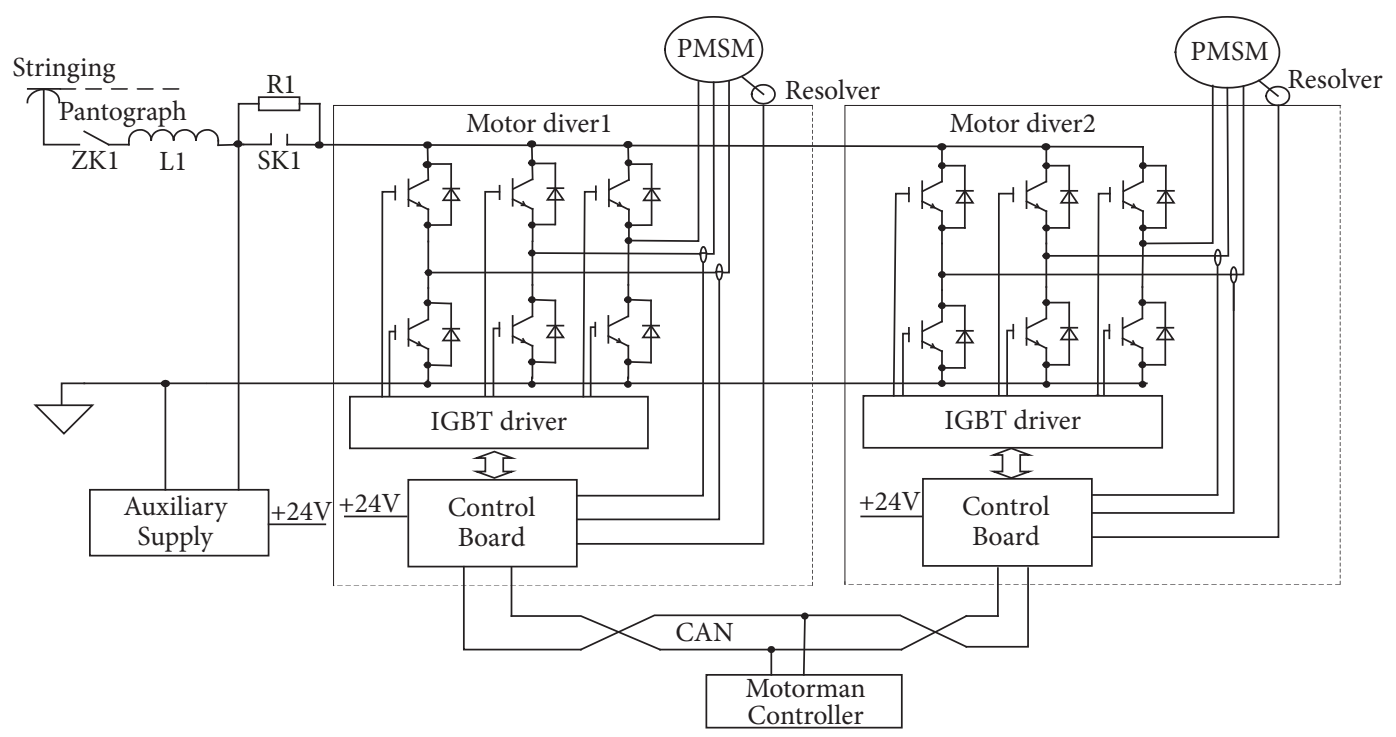

FIGURE 4: Electrical schematic diagram of the MTEL driving system.

TABLE 1: Parameters of PMSM.

\begin{tabular}{lc}
\hline Parameter & Value \\
\hline Rated power $(\mathrm{kW})$ & 22 \\
Pole pairs $P$ & 3 \\
Rated voltage $(\mathrm{V})$ & 380 \\
Rated current $(\mathrm{A})$ & 34.8 \\
Rated speed $(\mathrm{r} / \mathrm{min})$ & 1160 \\
Rated frequency $(\mathrm{Hz})$ & 58 \\
Rated torque $(\mathrm{N} \cdot \mathrm{m})$ & 181 \\
Rotary inertia $J\left(\mathrm{~kg} \cdot \mathrm{m}^{2}\right)$ & 0.21 \\
PM flux $\varphi(\mathrm{Wb})$ & 0.82 \\
Stator inductance $L(\mathrm{H})$ & 0.0153 \\
Friction coefficient $B$ & 0.001 \\
\hline
\end{tabular}

controller. MTEL operation state (such as forward, backward, stop) is controlled by the motorman controller. The PMSM driver is connected with the motorman controller through CAN communication. The control chip of the control board adopts TI company DSP chip TMS320F28335. The data that needs to be observed is exported by the analog ports Aol, Ao2 of the control board. The parameters of PMSM are listed in Table 1 .

By solving the LMI (13), the gain matrix of observer (5) is obtained as $L=\left[\begin{array}{lll}1 & 595.9-24.8 & 0\end{array}\right]^{T}$. Select the simulation parameters as $K=10, c_{1}=250, c_{2}=600, c_{3}=150, \partial=150$. By some calculations, it can be found that all the conditions of the DBS controller are satisfied.

4.1. Simulation Results. The initial torque of the motor is $0 \mathrm{~N} \cdot \mathrm{m}$, and the rotation speed is $1000 \mathrm{r} / \mathrm{min}$. At $0.4 \mathrm{~s}$ the external load suddenly becomes $140 \mathrm{~N} \cdot \mathrm{m}$. Then the external load suddenly return back to $0 \mathrm{~N} \cdot \mathrm{m}$ at $0.9 \mathrm{~s}$. A comparison is made between the proposed DBS control scheme and the traditional backstepping (TBS) control scheme. Figure 5

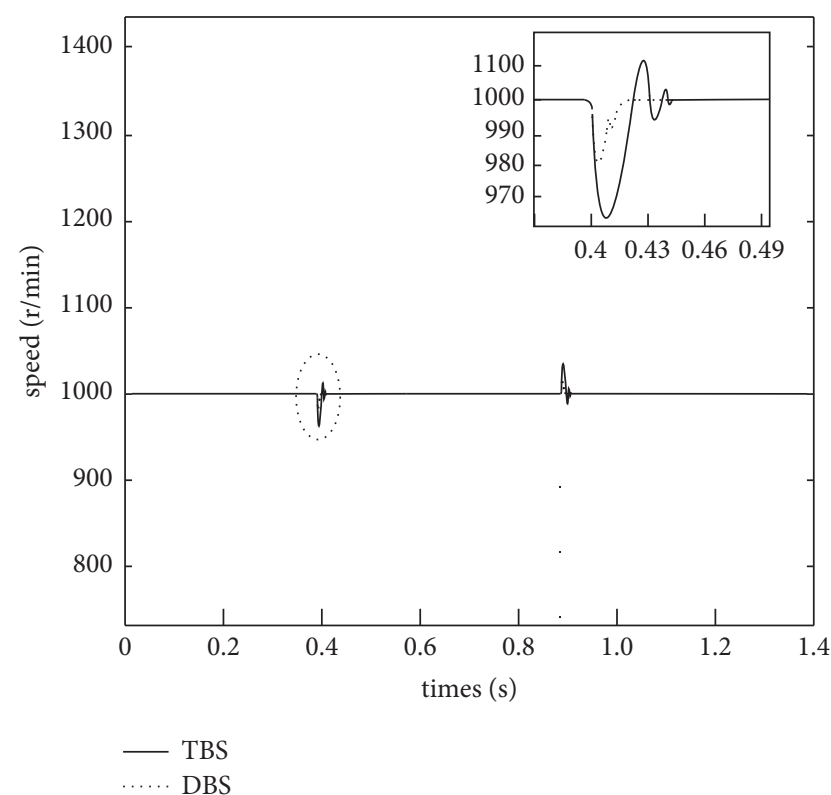

Figure 5: Speed responses.

shows that when TBS is adopted, the speed fluctuation range is $\pm 40 \mathrm{r} / \mathrm{min}$ and the stabilization time was $0.05 \mathrm{~s}$.

However, when DBS control scheme is applied, the speed fluctuation range is $\pm 20 \mathrm{r} / \mathrm{min}$ and the stabilization time was $0.02 \mathrm{~s}$. Figure 6 shows that the torque fluctuation range is $\pm 40 \mathrm{~N} \cdot \mathrm{m}$ of TBS, while the torque fluctuation range of DBS is $\pm 20 \mathrm{~N} \cdot \mathrm{m}$.

The three-phase currents of the TBS and DBS control scheme are shown in Figures 7 and 8, respectively. It can be seen that the DBS control method can track the reference rotation speed with smaller stability error, smaller overshoots, and less load torque fluctuations than that of the TBS method. 


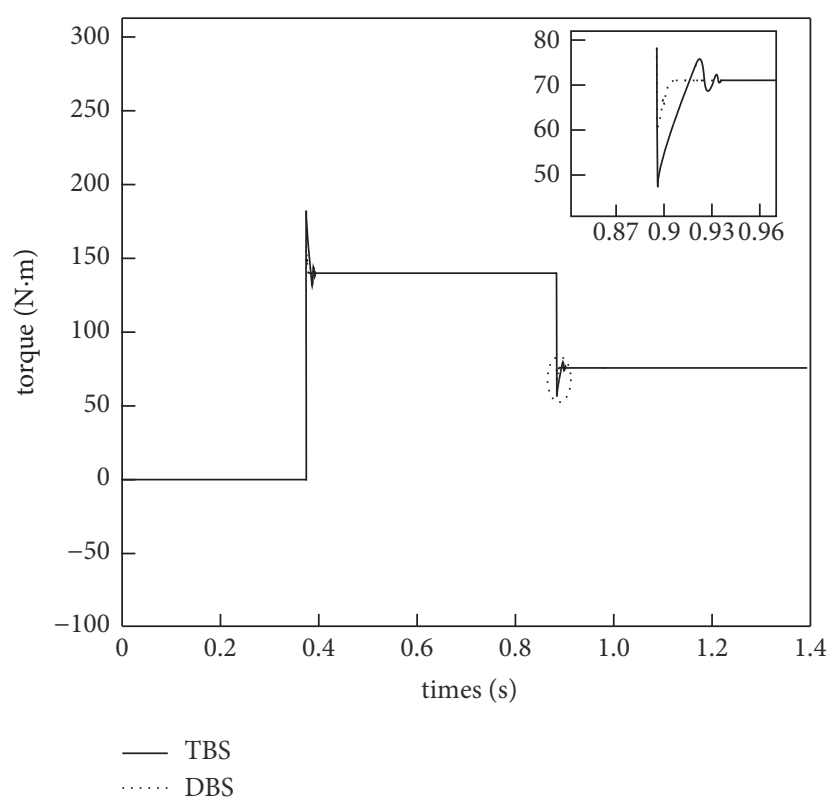

FIgURE 6: Torque responses.

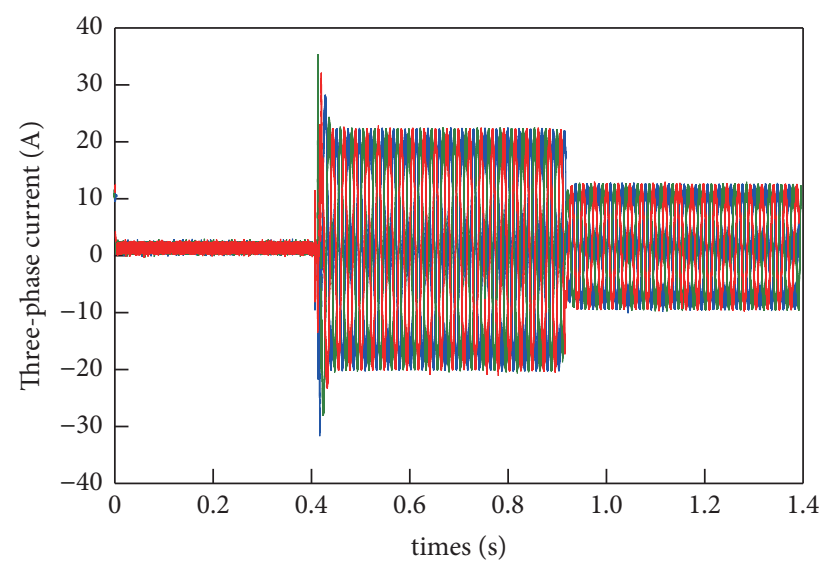

FIGURE 7: Three-phase currents of TBS.

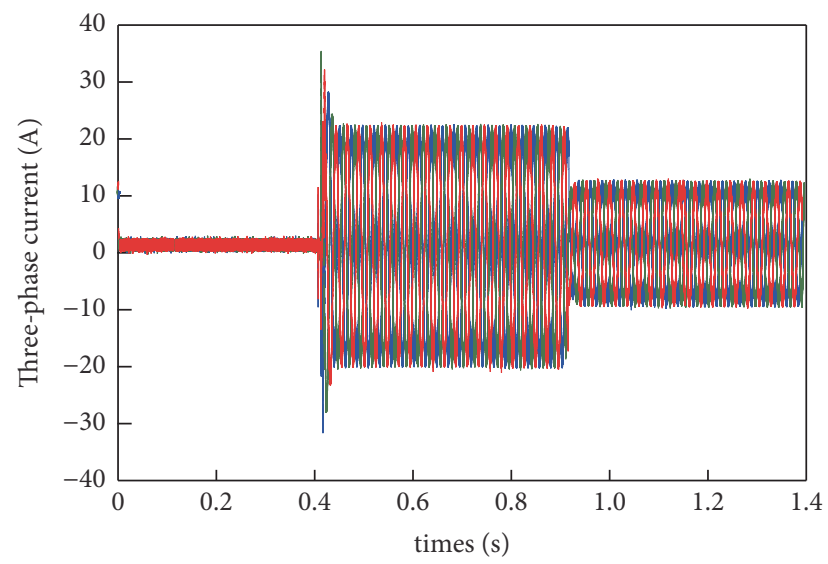

FIGURE 8: Three-phase currents of DBS.

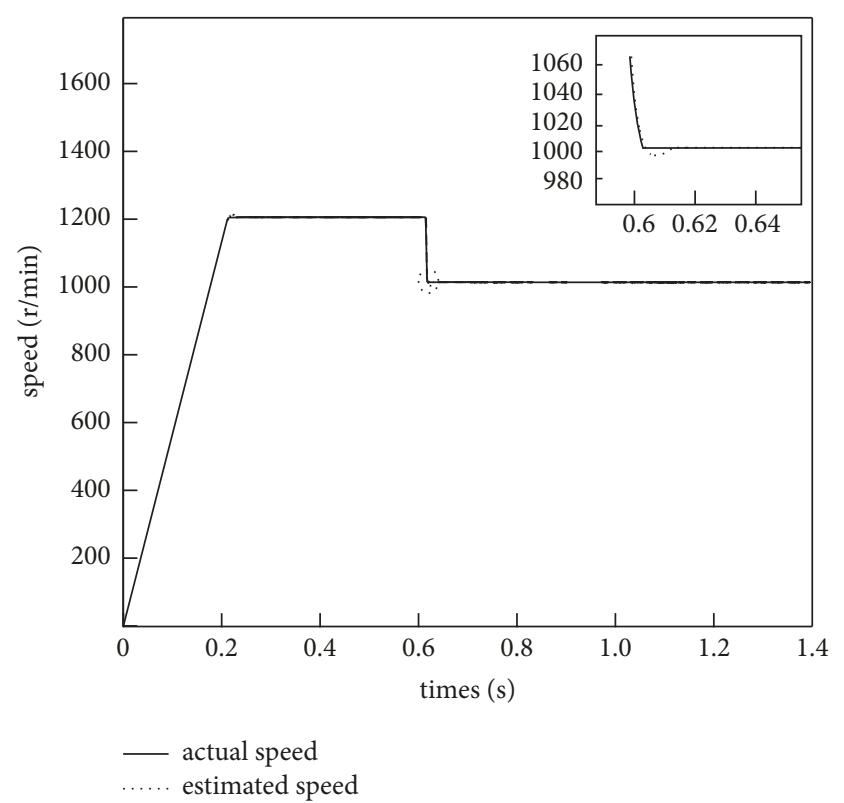

FIGURE 9: Estimated speed and actual speed.

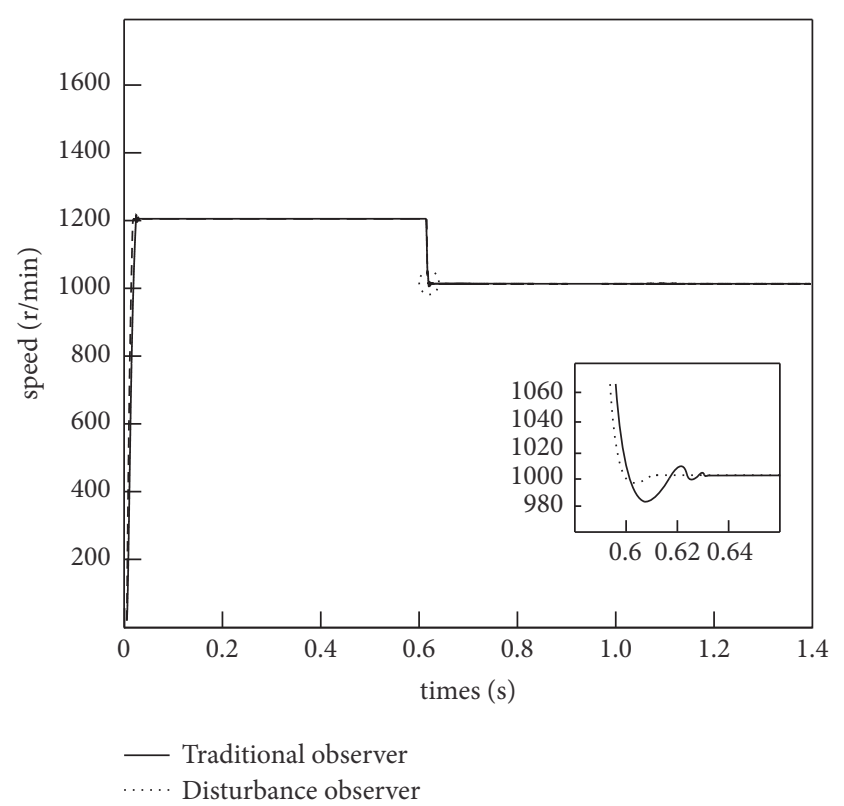

FIGURE 10: Estimated speed.

Figures 9 and 10 show actual and estimated speed when the LMI-based disturbance observer and traditional observer scheme $[16,18]$ are applied. It can be seen that the proposed observer can estimate the actual speed accurately, and it is more accurate, more efficient, and more stable than the traditional observer scheme.

4.2. Experimental Results. The results of the experiment are shown in Figures 11 and 12. The initial speed of the motor is $1000 \mathrm{r} / \mathrm{min}$, the load is $0 \mathrm{~N} \cdot \mathrm{m}$, the load is up to $140 \mathrm{~N} \cdot \mathrm{m}$ in 0.72 second, and the load is reduced to $70 \mathrm{~N} \cdot \mathrm{m}$ in 1.4 second. 


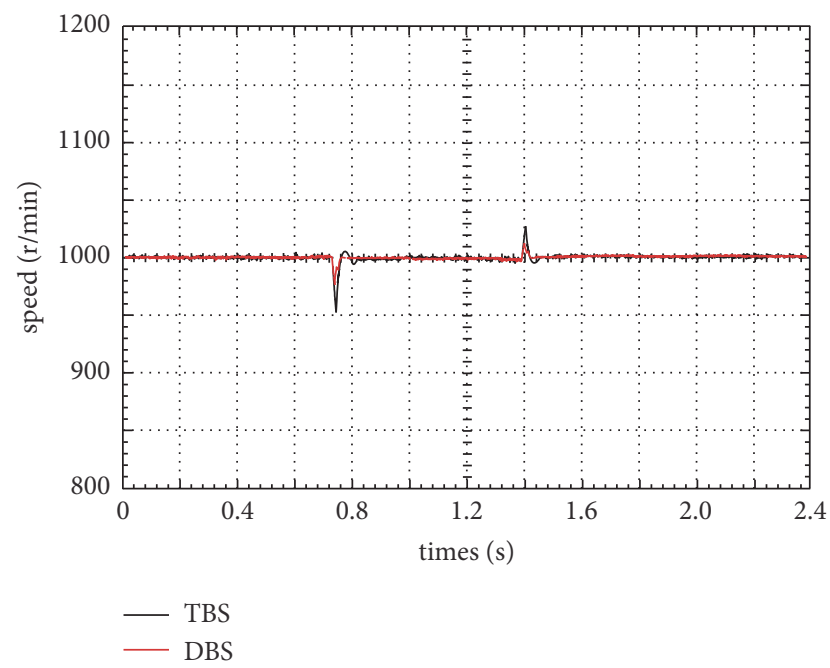

FIGURE 11: Speed response curve.

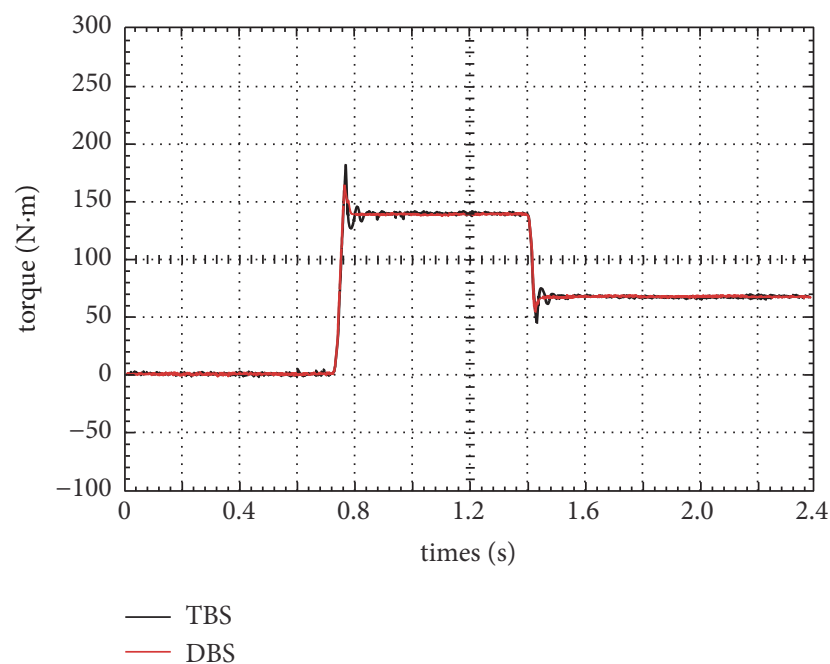

FIGURE 12: Torque response curve.

As can be seen in Figure 10, the torque fluctuation range of the TBS scheme is $\pm 40 \mathrm{~N} \cdot \mathrm{m}$ when the load torque is up to $140 \mathrm{~N} \cdot \mathrm{m}$ in 0.72 second and the stabilization time is 0.08 second; the torque fluctuation range of the DBS scheme is $\pm 20 \mathrm{~N} \cdot \mathrm{m}$ when the load torque is up to $140 \mathrm{~N} \cdot \mathrm{m}$ in 0.72 second and the stabilization time is 0.04 second. Three-phase current waveform of TBS scheme and DBS scheme are, respectively, shown in Figures 13 and 14, which illustrate the low ripple. The actual and estimated speed responses are shown in Figures 15 and 16 , which agree with the simulation result well.

\section{Conclusions}

In this paper, a disturbance observer-based (DOB) backstepping speed tracking control method has been presented for the speed tracking control of PMSM for MTEL. Through disturbance estimation, the DOB backstepping control strategy can achieve high precision speed tracking and disturbance

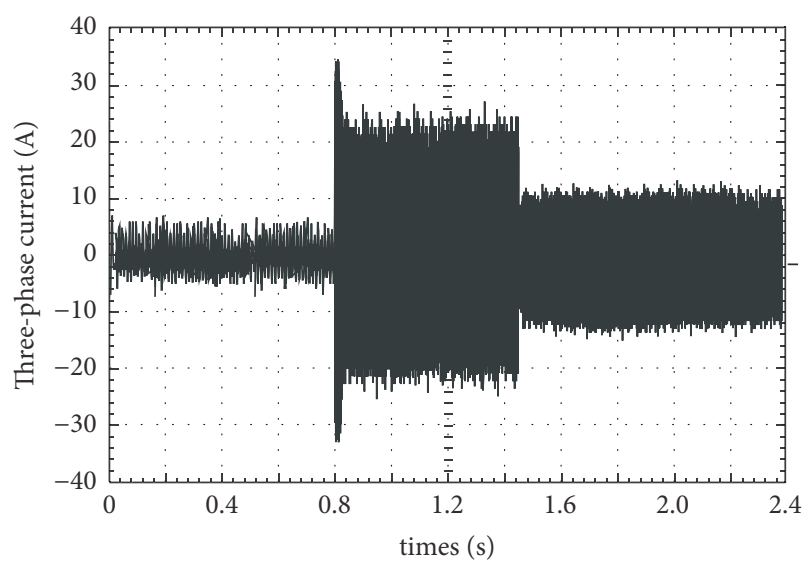

FIGURE 13: Three-phase currents of TBS.

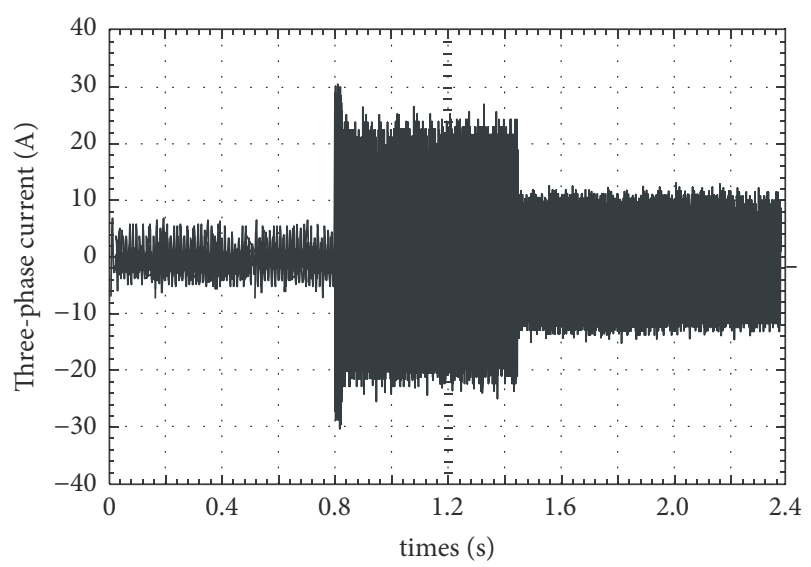

FIGURE 14: Three-phase currents of DBS.

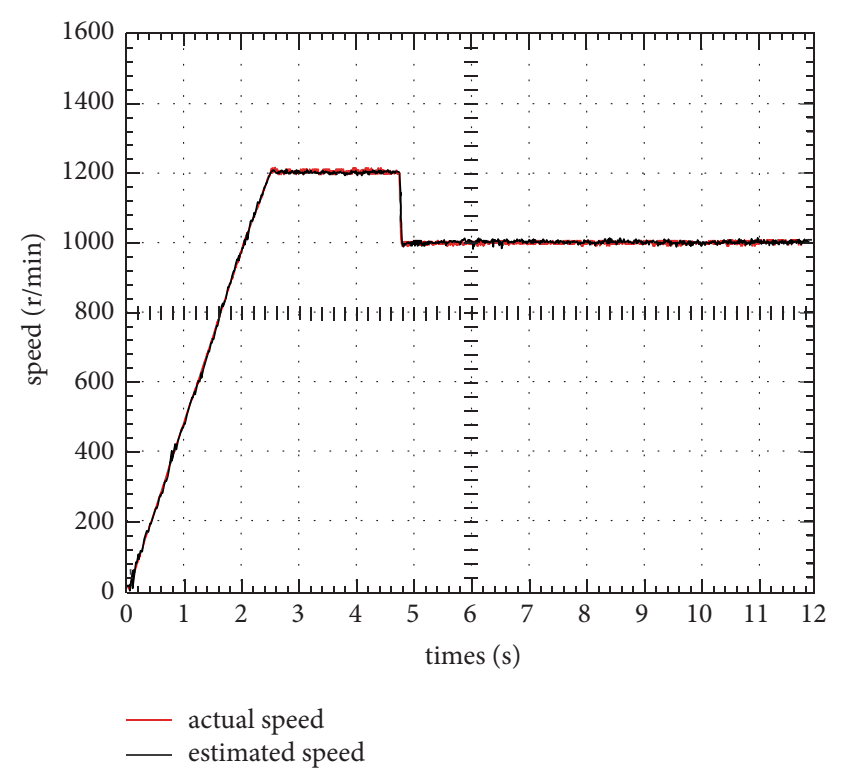

FIGURE 15: Estimated speed and actual speed. 


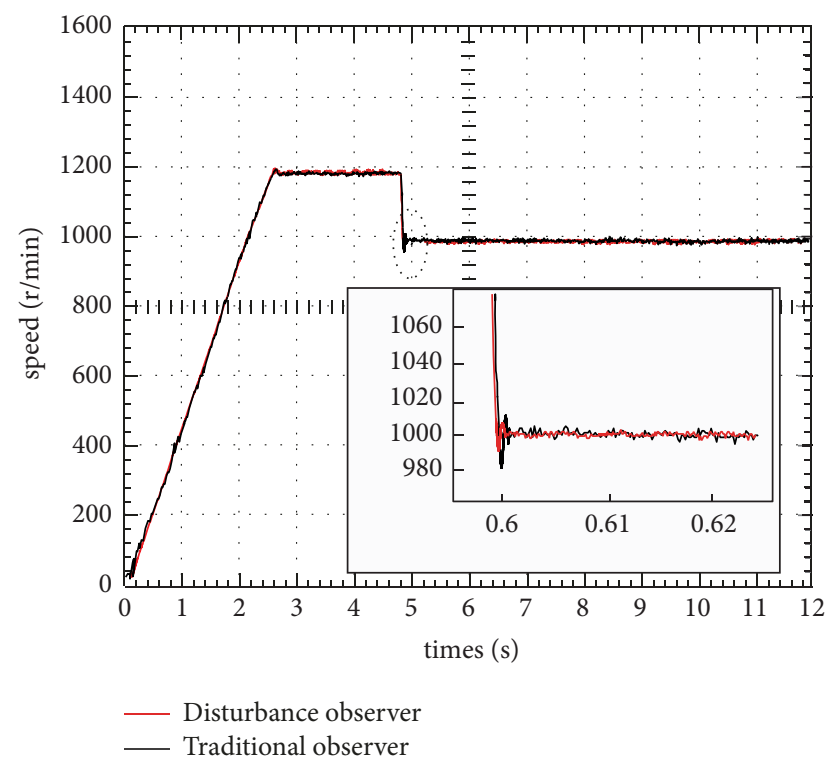

FIGURE 16: Estimation speed.

rejection performance. Both simulation and experimental results have shown the effectiveness of the proposed method.

\section{Conflicts of Interest}

The authors declare that there are no conflicts of interest regarding the publication of this paper.

\section{Acknowledgments}

This work was supported in part by the National Natural Science Foundation of China (61573298) and Scientific Research Fund of Hunan Provincial Education Department (15B238).

\section{References}

[1] J. Chiasson, Modeling and High-Performance Control of Electric Machines, IEEE Press/Wiley-Interscience, Piscataway, NJ, USA, 2005.

[2] J. Yu, P. Shi, H. Yu, B. Chen, and C. Lin, "Approximation-based discrete-time adaptive position tracking control for interior permanent magnet synchronous motors," IEEE Transactions on Cybernetics, vol. 45, no. 7, pp. 1363-1371, 2015.

[3] X. Yue, D. M. Vilathgamuwa, and K.-J. Tseng, "Observer-based robust adaptive control of PMSM with initial rotor position uncertainty," IEEE Transactions on Industry Applications, vol. 39, no. 3, pp. 645-656, 2003.

[4] G.-D. Andreescu, C. I. Pitic, F. Blaabjerg, and I. Boldea, "Combined flux observer with signal injection enhancement for wide speed range sensorless direct torque control of IPMSM drives," IEEE Transactions on Energy Conversion, vol. 23, no. 2, pp. 393-402, 2008.

[5] J. R. Dominguez, A. Navarrete, M. A. Meza, A. G. Loukianov, and J. Cañedo, "Digital sliding-mode sensorless control for surface-mounted PMSM," IEEE Transactions on Industrial Informatics, vol. 10, no. 1, pp. 137-151, 2014.
[6] E. Delaleau and A. M. Stankovic, "Flatness-based hierarchical control of the PMSM," in Proceedings of the American Control Conference, pp. 65-70, 2004.

[7] A. Khlaief, M. Boussak, and A. Châari, "A MRAS-based stator resistance and speed estimation for sensorless vector controlled IPMSM drive," Electric Power Systems Research, vol. 108, pp. 115, 2014.

[8] D. Liu, X. Zheng, and L. Cui, "Backstepping control of speed sensorless permanent magnet synchronous motor," Transactions of China Electrotechnical Society, vol. 26, no. 9, pp. 67-72, 2011.

[9] M. Karabacak and H. I. Eskikurt, "Design, modelling and simulation of a new nonlinear and full adaptive backstepping speed tracking controller for uncertain PMSM," Applied Mathematical Modelling: Simulation and Computation for Engineering and Environmental Systems, vol. 36, no. 11, pp. 5199-5213, 2012.

[10] X.-J. Xie, Z.-J. Li, and K. Zhang, "Semi-global output feedback control for nonlinear systems with uncertain time-delay and output function," International Journal of Robust and Nonlinear Control, vol. 27, no. 15, pp. 2549-2566, 2017.

[11] W.-H. Chen, "Disturbance observer based control for nonlinear systems," IEEE/ASME Transactions on Mechatronics, vol. 9, no. 4, pp. 706-710, 2004.

[12] X. G. Zhang, L. Z. Sun, K. Zhao, and L. Sun, "Nonlinear speed control for PMSM system using sliding-mode control and disturbance compensation techniques," IEEE Transactions on Power Electronics, vol. 28, no. 3, pp. 1358-1365, 2013.

[13] H. Wang, S. Li, H. Zhu, and S. He, "Generalized proportional integral observer based sliding mode control method for PMSM speed regulation system," in Proceedings of the 27th Chinese Control and Decision Conference, CCDC 2015, pp. 3463-3468, Qingdao, China, May 2015.

[14] A. A. Apte, V. A. Joshi, R. A. Walambe, and A. A. Godbole, "Speed control of PMSM using disturbance observer," IFACPapersOnLine, vol. 49, no. 1, pp. 308-313, 2016.

[15] L. Xiaoquan, L. Heyun, and H. Junlin, "Load disturbance observer-based control method for sensorless PMSM drive," IET Electric Power Applications, vol. 10, no. 8, pp. 735-743, 2016.

[16] J. Zhang, X. Liu, Y. Xia, Z. Zuo, and Y. Wang, "Disturbance observer-based integral sliding-mode control for systems with mismatched disturbances," IEEE Transactions on Industrial Electronics, vol. 63, no. 11, pp. 7040-7048, 2016.

[17] L. Song, Y. Wan, and T. Li, "Integral sliding mode control for permanent magnet synchronous motor based on load observer," in Proceedings of the 32nd Youth Academic Annual Conference of Chinese Association of Automation, YAC 2017, pp. 770-773, Hefei, China, May 2017.

[18] C.-X. Chen, Y.-X. Xie, and Y.-H. Lan, "Backstepping control of speed sensorless permanent magnet synchronous motor based on slide model observer," International Journal of Automation and Computing, vol. 12, no. 2, pp. 149-155, 2015.

[19] P. P. Khargonekar, I. R. Petersen, and K. Zhou, "Robust stabilization of uncertain linear systems: quadratic stabilizability and $H_{\infty}$ control theory," IEEE Transactions on Automatic Control, vol. 35, no. 3, pp. 356-361, 1990.

[20] L. Xie, "Output feedback $H_{\infty}$ control of systems with parameter uncertainty," International Journal of Control, vol. 63, no. 4, pp. 741-750, 1996. 


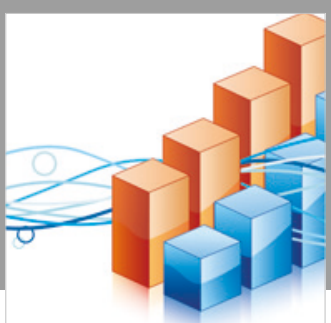

Advances in

Operations Research

\section{-n-m}
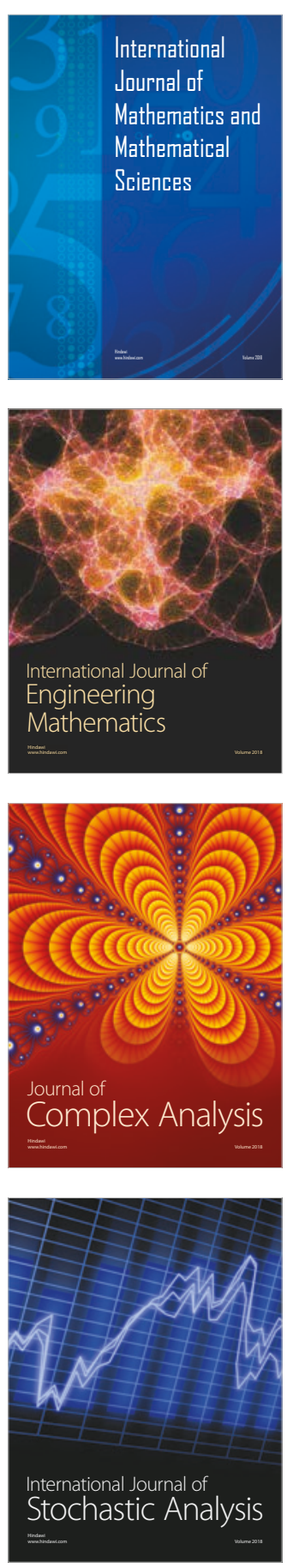
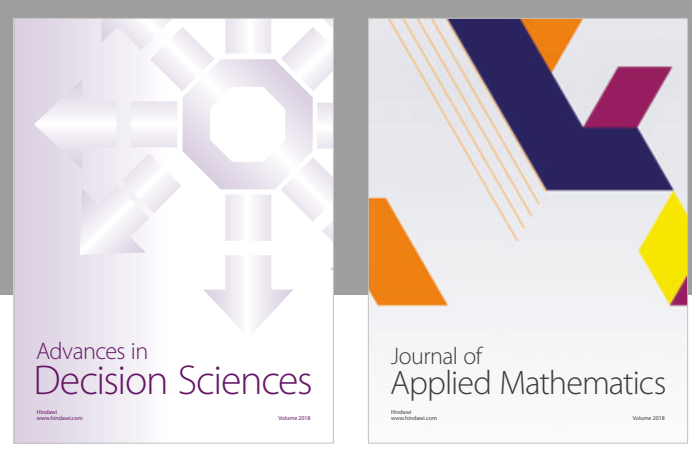

Journal of

Applied Mathematics
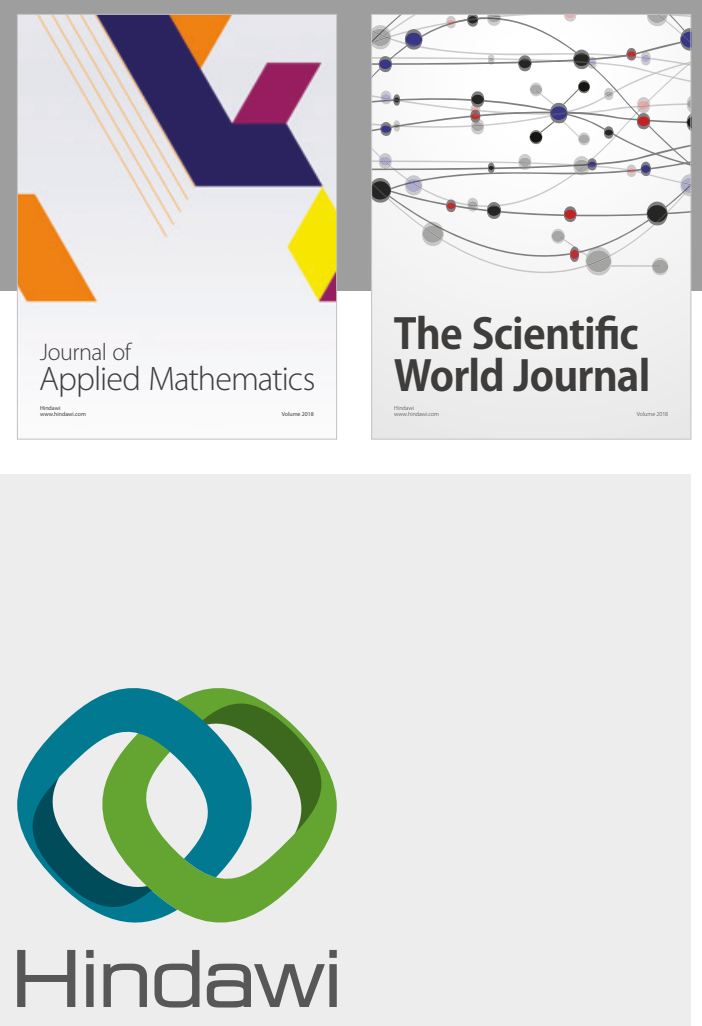

Submit your manuscripts at

www.hindawi.com

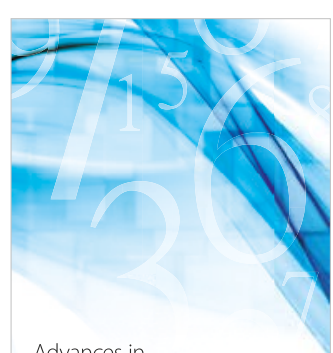

Advances in
Numerical Analysis
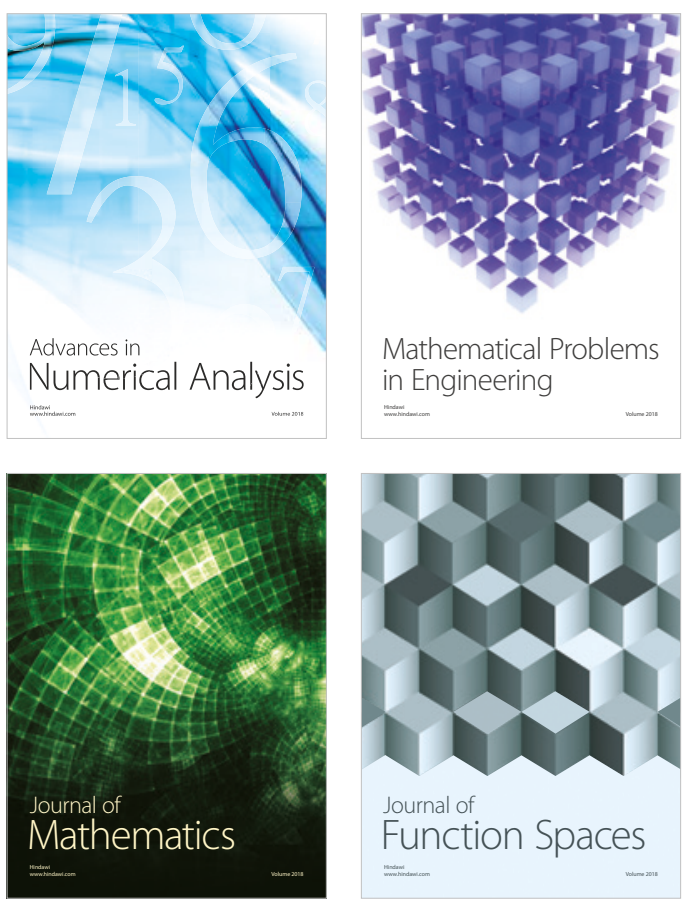

Mathematical Problems in Engineering

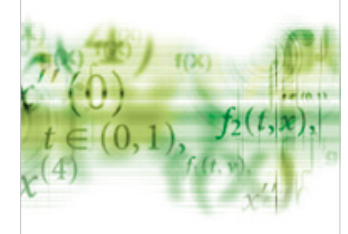

International Journal of

Differential Equations

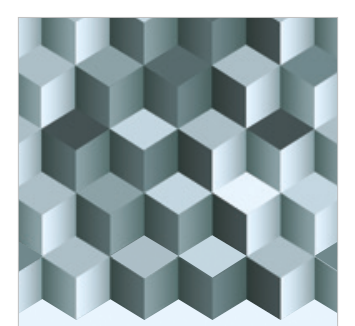

Journal of

Function Spaces

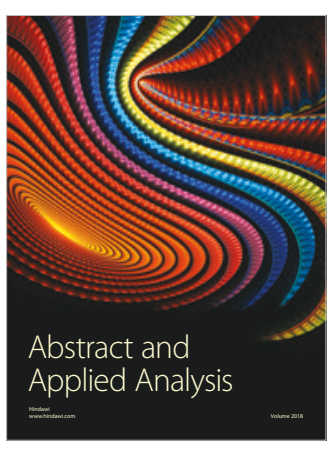

The Scientific

World Journal

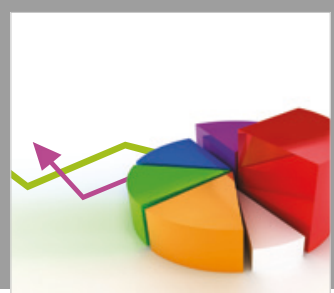

Journal of

Probability and Statistics
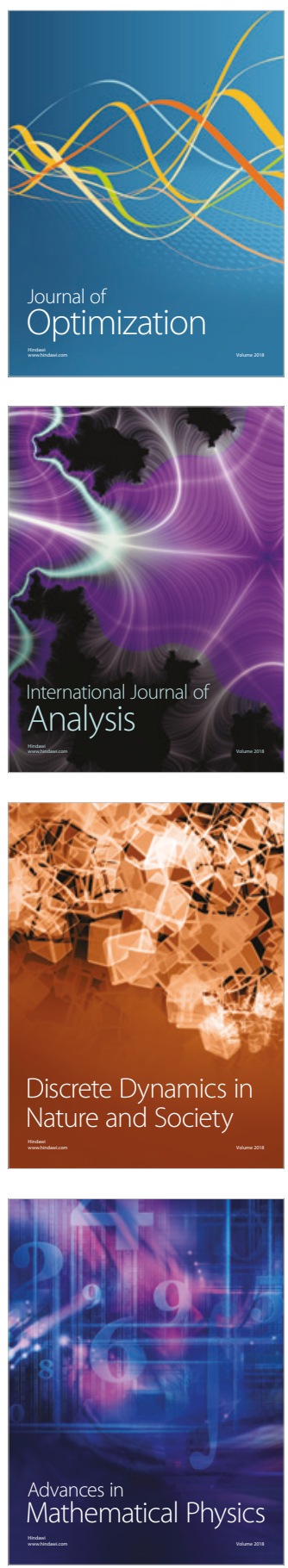